The World Environment Center was established in 1974. It provides information and technical assistance worldwide through conferences, meetings, publications, and the services of volunteers from US industry and also private citizens.
Whitman Bassow, President World Environment Center 605 Third Avenue, 17th Floor New York NY 10058, USA.

\title{
Detergents in France, Italy, and West Germany
}

A legislative decree laying down urgent measures to control water eutrophication has recently come into force in Italy. It bans the production, import, storage, and sale, of detergents exceeding specified levels of phosphorus (2 to $6 \%$ depending on the purpose of the detergent). (Decrettolegge No. 667.) (Italian National Agency.)

In France the Ministry of the Environment has just signed an agreement with detergent manufacturers. The composition of detergents must henceforth be detailed on the package, to reduce excess amounts of phosphates in the environment. (Ministère de l'Environnement, 14 Bd du Général Leclerc, F-92524 Neuilly-sur-Seine, Tel. 4758 12.)
The revision of the law on detergents in West Germany is primarily designed to improve environmental tolerance of detergents. However, it does not provide for acceptable general levels of particular components, nor will it reduce the use of detergents and other cleansing agents. (German National Agency.)

\section{COUNCIL OF EUROPE Centre Européen d'Information} pour la Conservation de la Nature BP 431 R6

F-67006 Strasbourg France.

\section{Alarming Depletion of Ozone Layer Above Antarctica: Scientists Seeking Cause}

Four teams of scientists will make a midwinter (in that continent) flight to Antarctica in August of this year to try to determine the cause of alarming annual deviations in the protective layer of ozone $\left(\mathrm{O}_{3}\right)$ above that continent. Ozone exists in very small amounts throughout the atmosphere but is concentrated principally in the 'ozone layer' or 'shield' situated about 15 miles $(24 \mathrm{~km})$ above the surface of the Earth. This shield of ozone is of critical importance to life on Earth, because it screens out almost all of the Sun's harmful ultraviolet radiation. Among other effects, scientists fear that a weakened ozone shield would increase the incidence of skin cancer and might seriously harm plant life.

World attention was focused on the problem in 1975 when it was suggested that the ozone layer might be affected by high-flying aircraft, agricultural fertilizers, and the use of 'freons' in aerosol sprays and refrigerators. More recently the ozone layer has startled the scientific world when a 50\% decrease has been observed in its abundance over Antarctica in the Antarctic spring-time-apparently very much greater than should be expected for the presentday atmosphere.

A scientific explanation for the annual ozone depletion phenomenon over Antarctica is vital to research workers, inter alia to correct computer models of the composition and dynamics of the stratosphere.

The four teams that are going to Antarctica include three scientists from the University of Wyoming, three from the State University of New York at Stony Brook (SUNY), four from the Jet Propulsion Laboratory (JPL) in Pasadena, California, and three from the National Oceanic and Atmospheric Administration. The ozone study, to be based in McMurdo Station-the principal US scientific outpost in Antarctica-is an interagency cooperative effort involving the National Science Foundation (NSF), the National Aeronautics and Space Administration (NASA), and the National Oceanic and Atmospheric Administration (NOAA). The Chemical Manufacturers' Association is supporting some of the research workers. The NSF provides operational support and manages all US activities in Antarctica.

The hazardous winter flight to McMurdo, called WINFLY, normally is restricted to moving scientists who are conducting experiments and personnel who are essential for the seasonal opening of that station on Ross Island. Because of the importance of the ozone study, one aircraft of the six that make the 2,100 -miles' $(3,360 \mathrm{~km})$ flight will be devoted to this National Ozone Expedition.

The Wyoming team will launch thirty 19,000-cubic-feet (ca $537 \mathrm{~m}^{3}$ ) balloons carrying ozone-measuring instruments and three 54,000-cubic-feet $\left(\mathrm{ca} 1,530 \mathrm{~m}^{3}\right)$ balloons carrying aerosol measuring devices. The SUNY team will use microwave measuring devices to determine molecular gases in the atmosphere. JPL scientists will measure absorption by atmospheric gases of solar infrared radiation. The NOAA team will measure the solar visible light that is scattered by other atmospheric constituents.

Recent studies have reported the large systematic changes in the ozone layer above Antarctica to be of 'unprecedented proportions'. The amount of ozone over Halley Bay, in the eastern portion of the Weddell Sea, has decreased every spring since 1975 , according to the British Antarctic Survey. The present ozone readings are about half the amount observed in the early 1970 s. Satellite data have shown that the spring ozone depletion is not confined to the Halley Bay region, but extends over most of Antarctica, creating a 'hole in the Ozone' about the size of the United States.

One puzzling aspect of the Antarctic ozone problem is that the dramatic deviations from expected amounts are believed to occur only in the local spring-from about midAugust to the end of October. The largest rate of ozone depletion occurs during September, suggesting that the ozone depletions may be linked to the return of sunlight to Antarctica, following the end of the 'polar night' period.

The 13 scientists who will concentrate on the ozone problem are among approximately 200 research workers and support personnel who will fly to McMurdo from Christchurch, New Zealand, to help prepare for the 198687 science season. They make the eight-hours' flight in ski-equipped C-130 aircraft owned by the NSF and flown by Navy pilots.

RaLPH KaZARIAN

National Science Foundation $1800 \mathrm{G}$ Street

Washington

DC 20550, USA. 